\title{
We are what they wear
}

\author{
What do you wear when you go to the dentist as a patient? What do \\ your patients wear to come to see you and what does that say about \\ your practice? asks Stephen Hancocks.
}

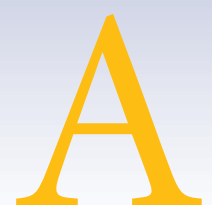

popular tagline to health education campaigns and indeed for healthy eating in general reads, 'you are what you eat'. It provides an interesting way of looking at ourselves and others in that, instead of a pile of wrinkled flesh we might visualise a heap of heavily buttered crumpets or a mound of chocolate fudge pudding. In similar vein, a lean, mean profile of rippling musculature might conjure up a plate of low-carb, crunchy fresh ingredients served as a salad.

But if we are what we eat how much more consciously is it the case that we are how we dress? Altering body shape takes weeks or months of disciplined work whereas plucking an item from a wardrobe or out of a drawer can express far more readily the image we want to

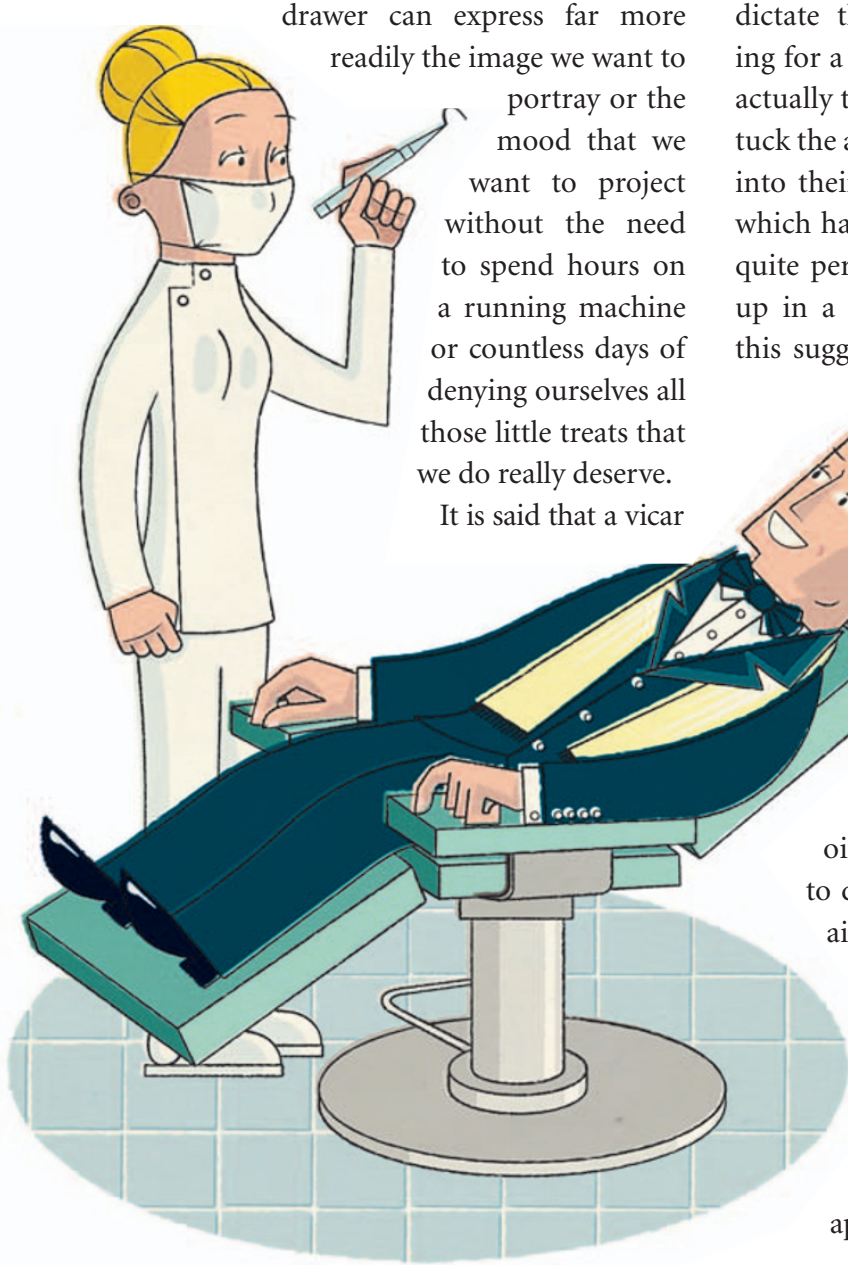
sees people at their best, a lawyer at their worst and a doctor as they really are. But what about a dental professional? Do patients consciously dress to come to a dental appointment and if so, how? It can of course be a wonderful pastime and provide great sport, giving marks out of ten for taste for the clothes patients wear. A sort of practice equivalent of the television shows that 'tactfully' suggest that a person's choice of apparel is less than flattering. It also leads to those delicious understatements for which the English language is so perfect: ' $\mathrm{Hmm}$, do you know I'm not sure I'd have gone for a lime green top if I had ginger hair,' or 'I really don't think that she makes the best of herself.'

It is quite possible though that the image that your patients have of the practice will dictate the way they dress when preparing for a visit. It is inevitable that people do actually think about this as they get ready to tuck the appointment card in their pocket or into their handbag. Ooh, which jacket and which handbag? Trying to 'read' this can be quite perplexing. If, for example, they turn up in a scruffy old t-shirt and jeans does this suggest that they think they are in for a messy session during which they are in danger of being showered with the deflections from the spittoon, smeared with impression material and covered in the dust from the trimming of dentures, crowns and veneers? I suppose

if they arrive in a sou'wester and oil skins the team really does need to do something about improving the aim of the three-in-one syringe.

The complete opposite might also apply. A very smartly dressed patient could be sending a subliminal message that they feel the visit is particularly important and they want you to appreciate the effort that they have gone to and the high regard in which they hold you. Or they could just be going on to somewhere else afterwards.

Coming from and going to will also dictate a lot of style choices. Work wear might be fine first thing in the morning but the clothes of those in sweaty, physical jobs can be somewhat less of delight to sit close by to later in the day. Sports kit is always an interesting one. Is the patient actually off to play a few sets of tennis or trounce an opposing soccer team or are they just going shopping? Some styles remain confusing.

Occasionally though we also get a glimpse of the unexpected or the otherwise hidden. Clothing rumpled in the chair or disturbed as the patient sits forward to rinse out might reveal a snapshot of underwear, an underpants waistband of alarming vivacity in the form of a pop-art print, something altogether more alluring but off limits as far as that all important confidentially is concerned. Mind you, him being a married man and all...!

On the joint topics of revelation and discretion however, there is one other item that some patients may wear, which they want us to see but don't necessarily want us to 'observe'. It is the humble toupee, rug, or more straightforwardly, wig. If the doctor sees people as they really are then we too have our fair share of that in the head division. Settled in the dental chair for the duration of a treatment session, the said hairpiece can easily become unseated or skewed, sometimes with remarkably funny consequences. The agony of this, however, is that you simply cannot laugh, smile, smirk or even acknowledge such an incident for fear of creating even more embarrassment, which makes it agonisingly funnier and even worse.

So, join your colleagues and check out the next half dozen patients with far greater scrutiny; what are they wearing and why, what does this say about them and how, and most importantly what does this indicate about their attitude to the practice? Oh, and then check out what you're wearing and ask the same questions. Happy dressing! 